\title{
Cr-N CO-DOPED ZnO NANOPARTICLES: SYNTHESIS, CHARACTERIZATION AND PHOTOCATALYTIC ACTIVITY FOR DEGRADATION OF THYMOL BLUE
}

\author{
Alebel Nibret ${ }^{1}$, O.P. Yadav ${ }^{2}$, Isabel Diaz ${ }^{3,4}$ and Abi M. Taddesse, ${ }^{2, *}$ \\ ${ }^{1}$ Department of Chemistry, University of the Free State, P.O. Box 339, South Africa \\ ${ }^{2}$ Department of Chemistry, Haramaya University, P.O. Box 138, Dire Dawa, Ethiopia \\ ${ }^{3}$ Instituto de Catálisis y Petroleoquímica, CSIC, c/Marie Curie 2, 28049 Madrid, Spain \\ ${ }^{4}$ Chemistry Department, Addis Ababa University, Addis Ababa, Ethiopia
}

(Received November 24, 2014; revised May 29, 2015)

\begin{abstract}
Here we report the synthesis of $\mathrm{CrN}$ co-doped $\mathrm{ZnO}$ for the first time. Zinc oxide $(\mathrm{ZnO})$ nanoparticles were synthesized by direct precipitation method via the reaction between zinc nitrate $\left[\mathrm{Zn}\left(\mathrm{NO}_{3}\right)_{2}\right.$ $\left..6 \mathrm{H}_{2} \mathrm{O}\right]$ and ammonium carbonate $\left[\left(\mathrm{NH}_{4}\right)_{2} \mathrm{CO}_{3}\right]$ in aqueous solutions with proper concentration. Modified photocatalysts were synthesized by the incipient wetness impregnation method (chromium-doped $\mathrm{ZnO}$ ) and by solid state reactions using $\mathrm{ZnO}$ and urea as precursors (nitrogen-doped $\mathrm{ZnO}$ ). Chromium-nitrogen co-doped $\mathrm{ZnO}$ nanomaterials were prepared from the already prepared $\mathrm{N}$-doped $\mathrm{ZnO}$ nanomaterials via one step impregnation method. The as-synthesized photocatalysts were investigated by XRD, BET, SEM-EDX, FTIR, and UV-Vis techniques. Photocatalytic degradation of thymol blue using as-synthesized photocatalysts was studied under visible as well as UV irradiations. Highest photocatalytic degradation efficiency of chromium-nitrogen co-doped zinc oxide could be attributed to the lower rate of recombination of the photo-generated electrons and holes as well as to its lower band gap energy as the result of the co-doping. Photocatalytic degradation is found to follow pseudo first order kinetics.
\end{abstract}

KEY WORDS: Photocatalysts, Precipitation method, Impregnation method, Co-doping, Zinc oxide, Thymol blue

\section{INTRODUCTION}

Presently, a wide variety of dyes are introduced into the aqueous system from various sources, such as industrial effluent, agricultural runoff, municipal wastes and chemical spills. Their toxicity, stability to natural decomposition and persistence in the environment has been the cause of much concern to societies and regulatory bodies around the world [1]. Thymol blue (TB) is used in the textile, leather goods, industrial paints, food, plastics, cosmetics, and consumer electronic sectors [2]. A sizable fraction of this is lost during the dyeing process and is released in the effluent water streams from the above industries. Therefore, decolorization and detoxification of organic dye effluents have taken an increasingly important environmental significance in recent years. As a result, pollutants that are emitted from various sources pose severe ecological problem as the bio-degradation of these pollutants is often very slow and conventional treatments are mostly ineffective and not environmentally sound to cope up with the stringent legislative requirement. In this regard, application of photocatalysis, especially using semiconductor such as $\mathrm{ZnO}$, appears to be more appealing approach than the conventional chemical oxidation methods for decomposition of toxic compounds to non-hazardous product [3]. This is because of the fact that semiconductors are: (i) inexpensive, (ii) non-toxic, (iii) having high surface area, (iv) having broad absorption spectra with high absorption coefficients and (v) affording facility for multi electron transfer process. $\mathrm{ZnO}$ has been demonstrated as an improved photocatalyst as compared to commercialized $\mathrm{TiO}_{2}$ based on its larger initial rate of activities and higher absorption efficacy of solar radiations [4]. However, $\mathrm{ZnO}$ has almost the same band gap as $\mathrm{TiO}_{2}$. Surface area and surface defects play an important role in the photocatalytic activities of metal oxide. The reason is that, doping of metal oxide with metal

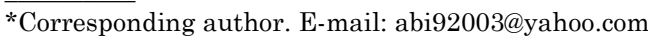


and/or transition metals increases the surface defects [5]. In addition, it affects the optical and electronic properties [6] and can presumably shift the optical absorption towards the visible region. This can subsequently activate these modified metal oxide photocatalysts upon visible light irradiation. Doping of $\mathrm{ZnO}$ with cobalt $(\mathrm{Co})$ has been reported [7] to cause hyperchromic shift in the optical absorption of $\mathrm{ZnO}$, which is attributable to the shrinkage of the band gap. These changes in $\mathrm{ZnO}$ caused by $\mathrm{Co}$ ion were assumed to play an important role in the photocatalysis. $\mathrm{ZnO}$ has several drawbacks including the fast recombination rate of photogenerated electron-hole pair, low quantum yield in the photocatalytic reactions in aqueous solutions and photocorrosion which obstruct commercialization of the photocatalytic degradation process. Even if various modification techniques are reported in the literature, neither metal nor non-metal doping alone can solve the above problems and there is still dearth of knowledge on metal-non metal co-doping. Reports related to $\mathrm{Cr}$ doped $\mathrm{ZnO}$ or $\mathrm{N}$ doped $\mathrm{ZnO}$ are well documented [8-11]. However, to the best of the researchers' knowledge, no work is reported on the effect of $\mathrm{ZnO}$ nanoparticles modified with $\mathrm{Cr}$ and $\mathrm{N}$ co-doping for degradation of thymol blue. Therefore, the impetus behind this study was to study the effect of $\mathrm{Cr}$ and $\mathrm{N}$ codoping in $\mathrm{ZnO}$ nanoparticles on the photocatalytic degradation of thymol blue.

\section{Materials}

\section{EXPERIMENTAL}

Chemicals used were: zinc nitrate hexahydrate $\left(\left[\mathrm{Zn}\left(\mathrm{NO}_{3}\right)_{2} \cdot 6 \mathrm{H}_{2} \mathrm{O}\right]\right.$, MW: $297.37 \mathrm{~g} / \mathrm{mol}>99.9 \%$, Shanghai), ammonium carbonate $\left(\left(\mathrm{NH}_{4}\right)_{2} \mathrm{CO}_{3}, \mathrm{MW}: 96 \mathrm{~g} / \mathrm{mol}>99 \%\right.$, Aldrich), ethanol $\left(\left[\mathrm{C}_{2} \mathrm{H}_{5} \mathrm{OH}\right], \mathrm{MW}: 46 \mathrm{~g} / \mathrm{mol}, 95 \%\right.$, Merck and Aldrich), chromium nitrate nonahydrate $\left(\left[\mathrm{Cr}\left(\mathrm{NO}_{3}\right)_{3} \cdot 9 \mathrm{H}_{2} \mathrm{O}\right], \mathrm{MW}: 399.996 \mathrm{~g} / \mathrm{mol}>99.9 \%\right.$, Merck), urea $\left[\mathrm{CO}\left(\mathrm{NH}_{2}\right)_{2}\right], \mathrm{MW}: 60.06 \mathrm{~g} / \mathrm{mol}$, Blulux), zinc oxide ( $\mathrm{ZnO}, \mathrm{MW}: 81.37 \mathrm{~g} / \mathrm{mol}$, min assay $99.0 \%)$, sodium hydroxide $(\mathrm{NaOH}$, MW: $40 \mathrm{~g} / \mathrm{mol}, 98 \%$, Merck), thymol blue $\left(\left[\mathrm{C}_{27} \mathrm{H}_{30} \mathrm{O}_{5} \mathrm{~S}\right]\right.$, MW: $466.60 \mathrm{~g} / \mathrm{mol}$, Canada, min dye content $95 \%$, abs. max. $472-475 \mathrm{~nm}$ at $\mathrm{pH} 8.10$ ). The color of aqueous thymol blue solution in the transition $\mathrm{pH}$ range $1.2-2.8,7.8-9.8$ is red to yellow and yellow to blue, respectively. It has melting point of $221-224{ }^{\circ} \mathrm{C}$. The structure of thymol blue is given in Figure 1.

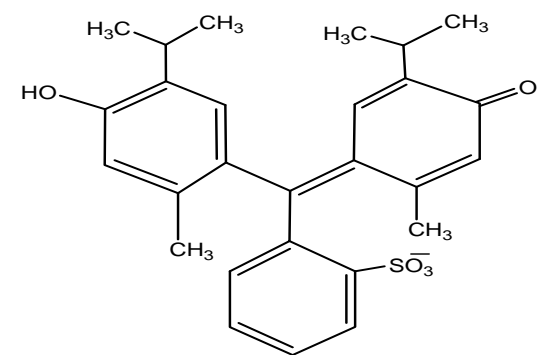

Figure 1. Structural formula of thymol blue $\left(\mathrm{C}_{27} \mathrm{H}_{30} \mathrm{O}_{5} \mathrm{~S}\right)$.

\section{Synthesis of photocatalyst}

Preparation of $\mathrm{ZnO}$ nanoparticles. $\mathrm{ZnO}$ nanoparticles were synthesized by precipitation method. Zinc nitrate hexahydrate $\left[\mathrm{Zn}\left(\mathrm{NO}_{3}\right)_{2} \cdot 6 \mathrm{H}_{2} \mathrm{O}\right]$ and ammonium carbonate $\left[\left(\mathrm{NH}_{4}\right)_{2} \mathrm{CO}_{3}\right]$ solutions were separately prepared by dissolving $40.0 \mathrm{~g}$ of $\left[\mathrm{Zn}\left(\mathrm{NO}_{3}\right)_{2} \cdot 6 \mathrm{H}_{2} \mathrm{O}\right]$ and $33.0 \mathrm{~g}$ of $\left(\mathrm{NH}_{4}\right)_{2} \mathrm{CO}_{3}$ in $100 \mathrm{~mL}$ of deionized water. The $\left[\mathrm{Zn}\left(\mathrm{NO}_{3}\right)_{2} \cdot 6 \mathrm{H}_{2} \mathrm{O}\right]$ solutions were slowly dripped into $\left(\mathrm{NH}_{4}\right)_{2} \mathrm{CO}_{3}$ solution and the mixture was stirred continuously for $2 \mathrm{~h}$. The precipitate resulting from the reaction between the two solutions was allowed to settle down for $24 \mathrm{~h}$, filtered with $0.2 \mu \mathrm{m}$ membrane filter (Whatman) and washed three times each with DI water and 
ethanol. The filtered/washed precipitate was dried at $100{ }^{\circ} \mathrm{C}$ to form the precursor for $\mathrm{ZnO}$. The precursor thus obtained, after drying was calcined at $550{ }^{\circ} \mathrm{C}$ for $2 \mathrm{~h}$ in programmable furnace to get the nano- $\mathrm{ZnO}$ particles [12].

Preparation of Cr-doped $\mathrm{ZnO}$ nanoparticles. $\mathrm{Cr}$ (4\%) doped $\mathrm{ZnO}$ was prepared by the incipient wetness impregnation method. $2.214 \mathrm{~g}$ of chromium nitrate nonahydrate $\left[\mathrm{Cr}\left(\mathrm{NO}_{3}\right)_{3} \cdot 9 \mathrm{H}_{2} \mathrm{O}\right]$ was dissolved in $100 \mathrm{~mL}$ of deionized water and then was added to $10 \mathrm{~g}$ of undoped $\mathrm{ZnO}$ and the mixture was stirred continuously for $1 \mathrm{~h}$. The product was allowed to settle down for $24 \mathrm{~h}$, filtered with $0.2 \mu \mathrm{m}$ membrane filter and washed three times each with DI water and ethanol. The filtered/washed precipitate was dried at $105^{\circ} \mathrm{C}$ for $12 \mathrm{~h}$, after drying was calcined at $550{ }^{\circ} \mathrm{C}$ for $2 \mathrm{~h}$ in programmable furnace [13]. The product obtained was labeled as chromium-doped zinc oxide $(\mathrm{CrZ})$.

Preparation of $\mathrm{N}$-doped zinc oxide nanoparticles. $\mathrm{N}$-doped $\mathrm{ZnO}$ was synthesized using solid state reaction. As-synthesized zinc oxide $(15 \mathrm{~g})$ was added to urea $(30 \mathrm{~g})$, ground in an agate mortar, and mixed well. The mixture was calcined in a ceramic crucible at $450{ }^{\circ} \mathrm{C}$ for $2 \mathrm{~h}$, cooled to room temperature and was ground in an agate mortar [14]. The product obtained was labeled as nitrogen-doped zinc oxide (NZ).

Preparation of $\mathrm{Cr}-\mathrm{N}$ co-doped $\mathrm{ZnO}$ nanoparticles. $\mathrm{Cr}$ (1.4\%) doped $\mathrm{N}-\mathrm{ZnO}$ was prepared by impregnation method. As-synthesized $\mathrm{N}$-doped $\mathrm{ZnO}(5 \mathrm{~g})$ and $5 \mathrm{~mL} 0.2 \mathrm{M} \mathrm{Cr}\left(\mathrm{NO}_{3}\right)_{3} .9 \mathrm{H}_{2} \mathrm{O}$ solution were mixed in a crucible. After agitating with a glass rod, the crucible was transferred to an oven for drying at $105{ }^{\circ} \mathrm{C}$ for $40 \mathrm{~min}$. The powder was calcined at $550{ }^{\circ} \mathrm{C}$ for $2 \mathrm{~h}$, cooled to room temperature and labeled as $\mathrm{Cr}-\mathrm{N}$ co-doped $\mathrm{ZnO}(\mathrm{CrNZ})$.

\section{Characterization of the as-synthesized photocatalysts}

Powder X-ray diffraction (XRD) patterns were collected with a Philips X'PERT diffractometer equipped with an $\mathrm{X}^{\prime}$ Celerator detector and using $\mathrm{Cu} \mathrm{K}_{\alpha}$ radiation $(\lambda=1.5405 \AA)$. The data were registered with $2 \theta$ steps of $0.02^{\circ}$ and accumulation time $20 \mathrm{~s}$. Nitrogen adsorption/desorption isotherms, were measured at $-196{ }^{\circ} \mathrm{C}$ in a Micromeritics ASAP 2420 device. Before the registration of the isotherms samples were degassed at $350{ }^{\circ} \mathrm{C}$ under high vacuum for at least 18 h. Surface areas were estimated by the BET method. The morphology of the solids and particle distribution sizes were determined by scanning electron microscopy (SEM) using a Hitachi TM1000 with EDX detector. The as-synthesized photocatalysts were characterized using FTIR (Shimidazu) instrument and measurements were performed with pressed pellets $(\mathrm{KBr})$ made using Paraffin as diluent. For the estimation of absorption edge of the as-synthesized photocatalysts, UV-Vis diffuse absorption was measured using SP65 spectrophotometer in the scanning range of $200-800 \mathrm{~nm} .0 .1 \mathrm{~g}$ of the photocatalyst was dispersed in $50 \mathrm{~mL}$ of deionized water and the absorbance data was recorded as a function of wavelength.

\section{Photocatalytic degradation studies}

Catalytic activities of the as-synthesized photocatalysts were studied for degradation of thymol blue (TB). The experiments were carried out under both visible light (472 nm) and ultraviolet illumination $(254 \mathrm{~nm})$ using as-synthesized photocatalysts. The photocatalytic reactor consists of a glass tube with an inlet tube for provision of air purging during photocatalysis and outlet tube for the collection of samples from the reactor at regular time intervals. $0.2 \mathrm{~g}$ of the assynthesized photocatalyst powder and $100 \mathrm{~mL}$ of aqueous solution of TB $(25 \mathrm{ppm})$ were taken in the reactor tube and the suspension was stirred in dark for $30 \mathrm{~min}$ to obtain adsorption/desorption equilibrium before irradiating the dye in the reactor [15]. The UV lamp 
(Philips) that predominantly emit at $254 \mathrm{~nm}$ with the definite power $12 \mathrm{~W}, 230 \mathrm{~V}$ and $50 \mathrm{~Hz}$ frequency was employed as UV source and tungsten lamp (TORCH) with definite power $40 \mathrm{~W}$, $220 \mathrm{~V}, 0.18 \mathrm{~A}$ and $50 \mathrm{~Hz}$ frequency was employed as visible source, and positioned parallel to the reactor. The distance between the top of reactor and lamp was $9 \mathrm{~cm} .10 \mathrm{~mL}$ of the sample was withdrawn at $20 \mathrm{~min}$ interval. The suspension was centrifuged at $3000 \mathrm{rpm}$ for $10 \mathrm{~min}$ and filtered to remove the catalyst particles before measuring absorbance. The absorbance of TB solution was determined at wavelength of $472 \mathrm{~nm}$ at $\mathrm{pH} 8.10$, and light intensity at 8.26 $\mathrm{mW} / \mathrm{cm}^{-2}$, and the percentage degradation of TB was calculated using the relation [16]:

$\%$ Degradation $=\left[\left(A_{0}-A_{t}\right) / A_{o}\right] \times 100$

where $A_{o}$ is absorbance of dye at initial stage, $A_{t}$ is absorbance of dye at time " $t$ ".

\section{RESULTS AND DISCUSSION}

The XRD patterns of calcined $\mathrm{ZnO}(\mathrm{Zc})$, N-doped $\mathrm{ZnO}(\mathrm{NZ}), \mathrm{Cr}$-doped $\mathrm{ZnO}(\mathrm{CrZ})$ and $\mathrm{Cr}-\mathrm{N}$ co-doped $\mathrm{ZnO}(\mathrm{CrNZ})$ are shown in Figure 2. The diffraction peaks at scattering angles $(2 \theta)$ : $31.8,34.4,36.4,47.5,56.6$, and 62.9 corresponds to the reflection from (100), (002), (101), (102), (110), and (103) crystal planes for all as-synthesized powders suggesting pure hexagonal wurtzite structure of $\mathrm{ZnO}$. Doping seemed to have apparently no effect on the zincite phase of $\mathrm{ZnO}$ as the XRD patterns of the doped materials are similar to the undoped $\mathrm{ZnO}$. Although the EDX results confirmed the successful doping of $\mathrm{Cr}$ into the as-synthesized $\mathrm{Cr}$-doped $\mathrm{ZnO}$ and $\mathrm{CrN}$ codoped $\mathrm{ZnO}$, no peaks corresponding to $\mathrm{Cr}_{2} \mathrm{O}_{3}$ or other $\mathrm{Cr}$-containing phases were detected in the doped XRD patterns. This could possibly be due to the lower concentration of $\mathrm{Cr}$ $(<5 \%)$ in the doped $\mathrm{ZnO}$ crystals. Observed pattern of diffraction peaks for undoped $\mathrm{ZnO}$ and $\mathrm{Cr}$-doped $\mathrm{ZnO}$ are identical in respect of their positions as well as intensities. Absence of such shifts in the recorded XRD indicates the segregation of $\mathrm{Cr}$ particles in the grain boundaries of $\mathrm{ZnO}$ or incorporation of only an insignificant quantity in the substitutional $\mathrm{Zn}$ site. The latter could be attributed to the similar ionic radius of $\mathrm{Cr}$ to that of $\mathrm{Zn}^{2+}$, which indicates that $\mathrm{Cr}^{3+}$ may penetrate into $\mathrm{ZnO}$ crystal $[17-18,28]$.

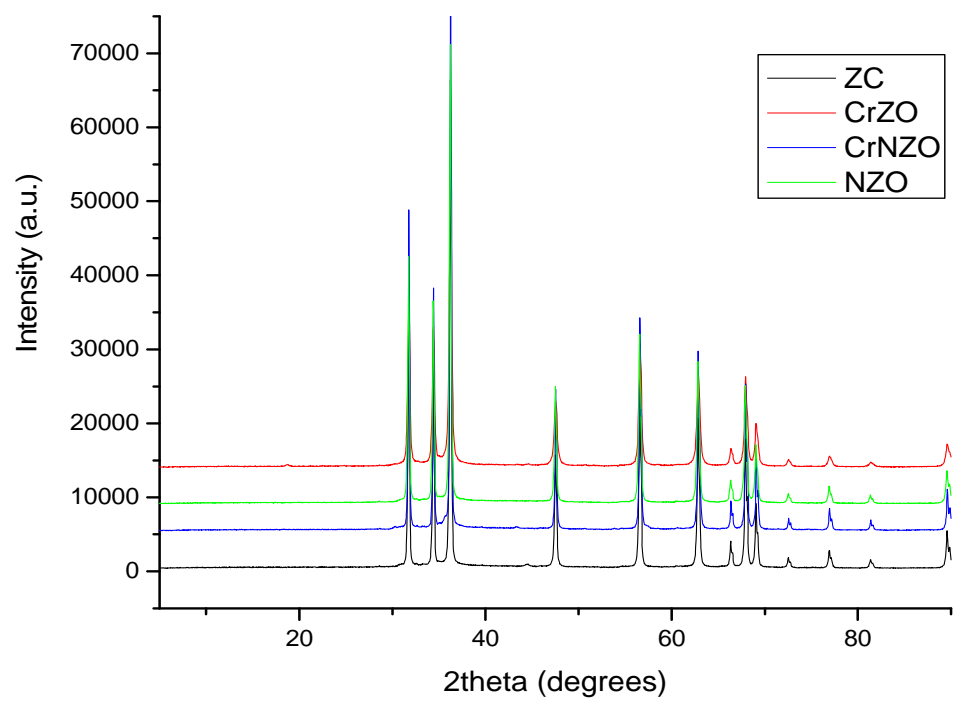

Figure 2. XRD patterns of calcined $\mathrm{ZnO}(\mathrm{ZC})$, N-doped $\mathrm{ZnO}(\mathrm{NZO}), \mathrm{C}) \mathrm{Cr}$-doped $\mathrm{ZnO}(\mathrm{CrZO})$, and $\mathrm{Cr}-\mathrm{N}$ co-doped $\mathrm{ZnO}(\mathrm{CrNZO})$.

Bull. Chem. Soc. Ethiop. 2015, 29(2) 
The average crystallite size of the as-synthesized photocatalysts can be calculated using the Debye-Scherrer formula [19]:

$\mathrm{D}=\frac{0.9 \lambda}{\beta \cos \theta}$

where $\mathrm{D}$ is the average crystallite size, $\lambda$ is the wavelength of the $\mathrm{X}$ rays $=0.15406 \mathrm{~nm}$ for $\mathrm{Cu}$ target $\mathrm{K}_{\alpha}$ radiation, $\beta$ is the peak width of half-maximum (FWHM) of an XRD, and $\theta$ is the Bragg diffraction angle. The most intense peak (101) in the XRD patterns was used to calculate the average crystalline size. The calculated average crystallite sizes (D) of the photocatalysts are given in Table 1. The order of average crystallite size (D) of as-synthesized photocatalysts is: $\mathrm{CrZ}<\mathrm{NZ}<\mathrm{CrNZ}<\mathrm{ZC}$. The specific surface area also included in Table 1 is in general relatively low but followed similar trend with the particle size obtained from the XRD (Table 1). The highest (3-4 fold larger) specific surface area is exhibited by $\mathrm{Cr}$ doped $\mathrm{ZnO}$. This could be attributed to the smallest size of this crystal $(25 \mathrm{~nm})$ compared with the other three with a size range between 33 and $38 \mathrm{~nm}$ roughly.

The SEM micrographs for all the as-synthesized nanomaterials are displayed in Figure 3. Aggregates of $\mathrm{ZnO}$ nanorods of a wide range of sizes are obtained for the $\mathrm{ZnO}$ crystals. The morphology of the nanorods is retained in all the doped cases except for $\mathrm{Cr}$-doped $\mathrm{ZnO}$ in which the smaller particle size reaches the limit of resolution of the microscope confirming again the trend of a smallest particle size in this sample. On the other hand, in the rest of the doped samples it is possible to observe a restrained growth of the nanorods due to the presence of the dopants. EDX analyses included in Table 1 indicated the presence of $\mathrm{Zn}$ in all types of $\mathrm{ZnO}$ crystals and $\mathrm{Cr}$ in both $\mathrm{Cr}$ doped and $\mathrm{CrN}$ co-doped samples. The presence of $\mathrm{Cr}$ in the $\mathrm{Cr}-\mathrm{ZnO}$ sample was very homogenous with values within 3 and $5 \%$ in close agreement with the $\mathrm{Cr}$ theoretical concentration. On the other hand, in the co-doped $\mathrm{Cr}-\mathrm{N}-\mathrm{ZnO}$ sample the $\mathrm{Cr}$ was heterogeneously detected along the crystals with a wide spectrum of compositions ranging from 0 to $28 \% \mathrm{Cr}$.

\section{UV-Vis absorption spectra}

The optical diffuse absorption spectra were determined using UV/Vis. spectroscopy. UV/Vis absorption spectra of the as-synthesized photocatalysts $\mathrm{ZnO}, \mathrm{N}-\mathrm{ZnO}, \mathrm{Cr}-\mathrm{ZnO}$ and $\mathrm{Cr}-\mathrm{N}$ codoped $\mathrm{ZnO}$ are shown in Figure 4. The respective absorption edges are found to be 378, 540, 434, and $572 \mathrm{~nm}$. It is clear that the absorption wavelength range of $\mathrm{N}-\mathrm{ZnO}$ powder is shifted to longer wavelength as compared to pure $\mathrm{ZnO}$ powder. The extension of absorption in the visible range can be attributed to the nitrogen doping. The delocalized N $2 p$ states of doped N, intermix with $\mathrm{O} 2 \mathrm{p}$ and metal $3 \mathrm{~d}$ states of photo-catalyst $\mathrm{ZnO}$. Such intermixing of doped N $2 p$ states with energy states of photo-catalyst near valence band (VB) narrows down the band gap [2021]. Cr-doped $\mathrm{ZnO}$ has also showed a red shift compared to the undoped $\mathrm{ZnO}$ although the band shift is not as pronounced as in the $\mathrm{N}$ doped $\mathrm{ZnO}$. This could be due to the band-gap narrowing resulting from the creation of dopant energy levels below the conduction band [22-23]. Further reduction in the band gap of the $\mathrm{Cr}-\mathrm{N}$ co-doped $\mathrm{ZnO}$ might be due to the synergetic effect of the two dopants.

Table 1. Average crystallite size (D) and specific surface area (SSA) of the as-synthesized photo-catalysts.

\begin{tabular}{|l|c|c|c|}
\hline Sample & $\mathrm{D}(\mathrm{nm})$ & $\mathrm{SSA}\left(\mathrm{m}^{2} / \mathrm{g}\right)$ & Content of Cr by EDX $(\%)$ \\
\hline $\mathrm{ZnO}$ & 38.4 & 5.1 & - \\
\hline $\mathrm{N}-\mathrm{ZnO}$ & 33.2 & 5.4 & - \\
\hline $\mathrm{Cr}-\mathrm{ZnO}$ & 25.2 & 16.9 & Homogeneous $3-5 \%$ \\
\hline $\mathrm{Cr}-\mathrm{N}-\mathrm{ZnO}$ & 36.5 & 4.2 & Non-homogeneous $0-28 \%$ \\
\hline
\end{tabular}




\section{SEM-EDX analysis}
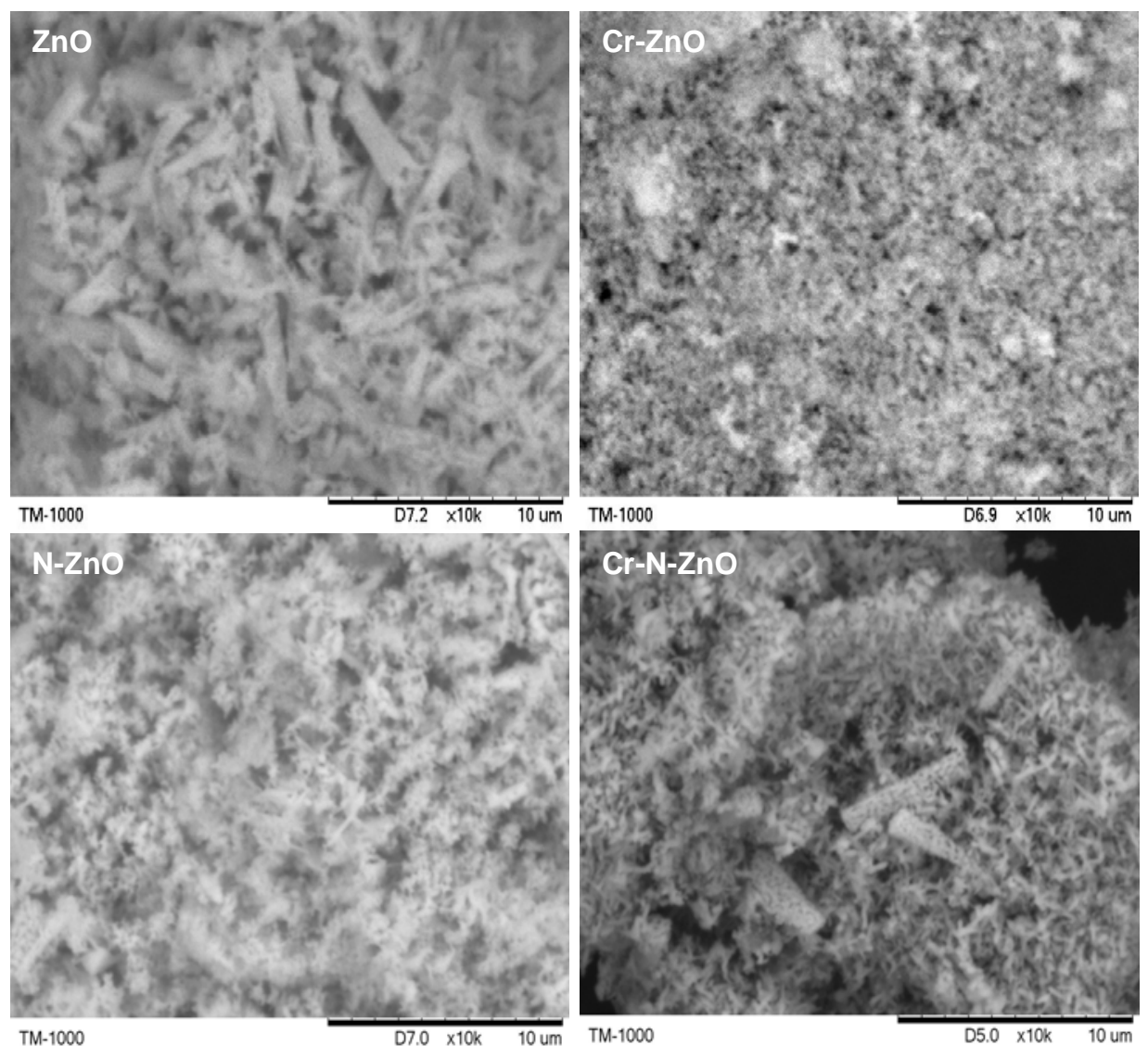

Figure 3. SEM micrograhs of $\mathrm{ZnO} \mathrm{N}$-doped $\mathrm{ZnO}, \mathrm{Cr}$-doped $\mathrm{ZnO}$ and $\mathrm{CrN}$ co-doped $\mathrm{ZnO}$ nanocrystals, all of them at $10.000 x$ Magnifications.

The band gap energy (Eg) of the as-synthesized photocatalysts was calculated using the equation depicted below [24]:

$E_{g}=(1240 \mathrm{eV}) / \lambda$

where, $E_{g}$ is band gap energy in electron volts and $\lambda$ is wavelength $(\mathrm{nm})$ corresponding to absorption edge. The $E_{g}$ of photocatalysts $\mathrm{Zc}, \mathrm{NZ}, \mathrm{CrZ}$, and $\mathrm{CrNZ}$ were found as 3.28, 2.30, 2.86 and $2.17 \mathrm{eV}$, respectively (Table 2 ). 


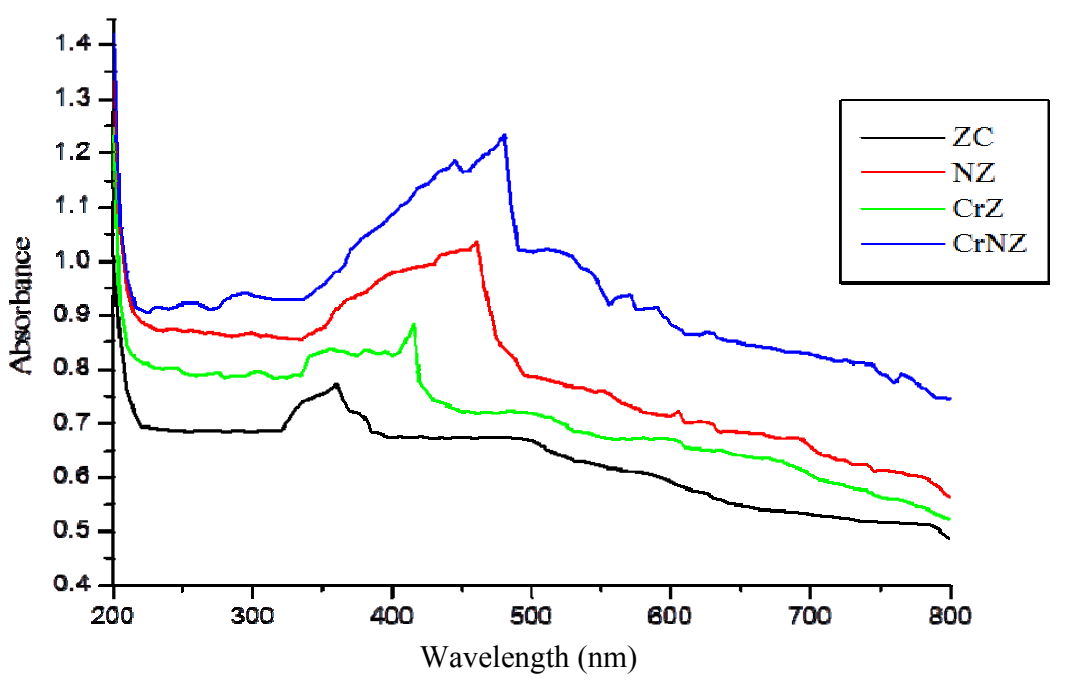

Figure 4. UV-Visible absorption spectra of calcined $\mathrm{ZnO}(\mathrm{Zc}), \mathrm{N}$-doped $\mathrm{ZnO}(\mathrm{NZ}), \mathrm{Cr}$-doped $\mathrm{ZnO}(\mathrm{CrZ})$ and $\mathrm{Cr}-\mathrm{N}$ co-doped $\mathrm{ZnO}(\mathrm{CrNZ})$ at absorption edges: 378, 540, 434 and $572 \mathrm{~nm}$, respectively.

Table 1. Absorbance, maximum wavelengths and band gaps of as-synthesized photocatalysts.

\begin{tabular}{|c|c|c|c|}
\hline Samples & Absorbance & Maximum wavelength $(\mathrm{nm})$ & Band gap $\left(\mathrm{E}_{\mathrm{g}}\right)(\mathrm{eV})$ \\
\hline $\mathrm{ZnO}$ & 0.773 & 378 & 3.28 \\
\hline $\mathrm{N}-\mathrm{ZnO}$ & 1.036 & 540 & 2.30 \\
\hline $\mathrm{Cr}-\mathrm{ZnO}$ & 0.884 & 434 & 2.86 \\
\hline $\mathrm{Cr}-\mathrm{N}-\mathrm{ZnO}$ & 1.213 & 572 & 2.17 \\
\hline
\end{tabular}

\section{FT-IR analysis}

Figures 5a-d show the FTIR spectra of the as-synthesized photocatalysts $\mathrm{ZnO}(\mathrm{Zc}), \mathrm{N}$-doped $\mathrm{ZnO}(\mathrm{NZ})$, Cr-doped $\mathrm{ZnO}(\mathrm{CrZ})$, and $\mathrm{Cr}-\mathrm{N}$ co-doped $\mathrm{ZnO}$ (CrNZ) respectively. Absorption bands in the range $3393-3443 \mathrm{~cm}^{-1}$ are ascribed to the O-H stretching vibrations of $\mathrm{H}_{2} \mathrm{O}$ adsorbed on the as-synthesized nanomaterials. The peaks in the range 1608 to $1637 \mathrm{~cm}^{-1}$ correspond to the $\mathrm{O}-\mathrm{H}$ bending vibrations of $\mathrm{H}_{2} \mathrm{O}$ adsorbed [25].

The bands for $\mathrm{O}-\mathrm{H}$ stretching and bending have become less intense and shifted to the lower frequencies in the case of $\mathrm{N}$ doping. This demonstrates that the $\mathrm{Zn}-\mathrm{O}$ bond has been altered due to $\mathrm{N}$ doping. The peaks in the range of $422-627 \mathrm{~cm}^{-1}$ correspond to the $\mathrm{Zn}-\mathrm{O}$ bond stretching. The bands observed at 823 and $882 \mathrm{~cm}^{-1}$ could be attributed to $\mathrm{Cr}-\mathrm{O}$ bond stretching evidencing the incorporation of $\mathrm{Cr}^{+3}$ in the host $\mathrm{ZnO}$ crystal. The weak peaks at 1392 and $1401 \mathrm{~cm}^{-1}$ for the $\mathrm{N}$-doped and $\mathrm{CrN}$ codoped $\mathrm{ZnO}$ could be attributed to the ammonium ions possibly produced by the dissociation of urea. The FTIR spectra did not present any of the characteristic bands of the urea, which are typically presented at $3210 \mathrm{~cm}^{-1}$ [26], thereby suggesting that urea species were significantly decomposed by the thermal treatment employed in the syntheses. The bands at $2913-2922 \mathrm{~cm}^{-1}$ are responsible for the symmetric C-H stretching where as the bands in the range of $2844-2854 \mathrm{~cm}^{-1}$ are due to asymmetric $\mathrm{C}-\mathrm{H}$ stretching. The appearance of these bands could be attributed to the presence of residual paraffin used as diluent [27]. 

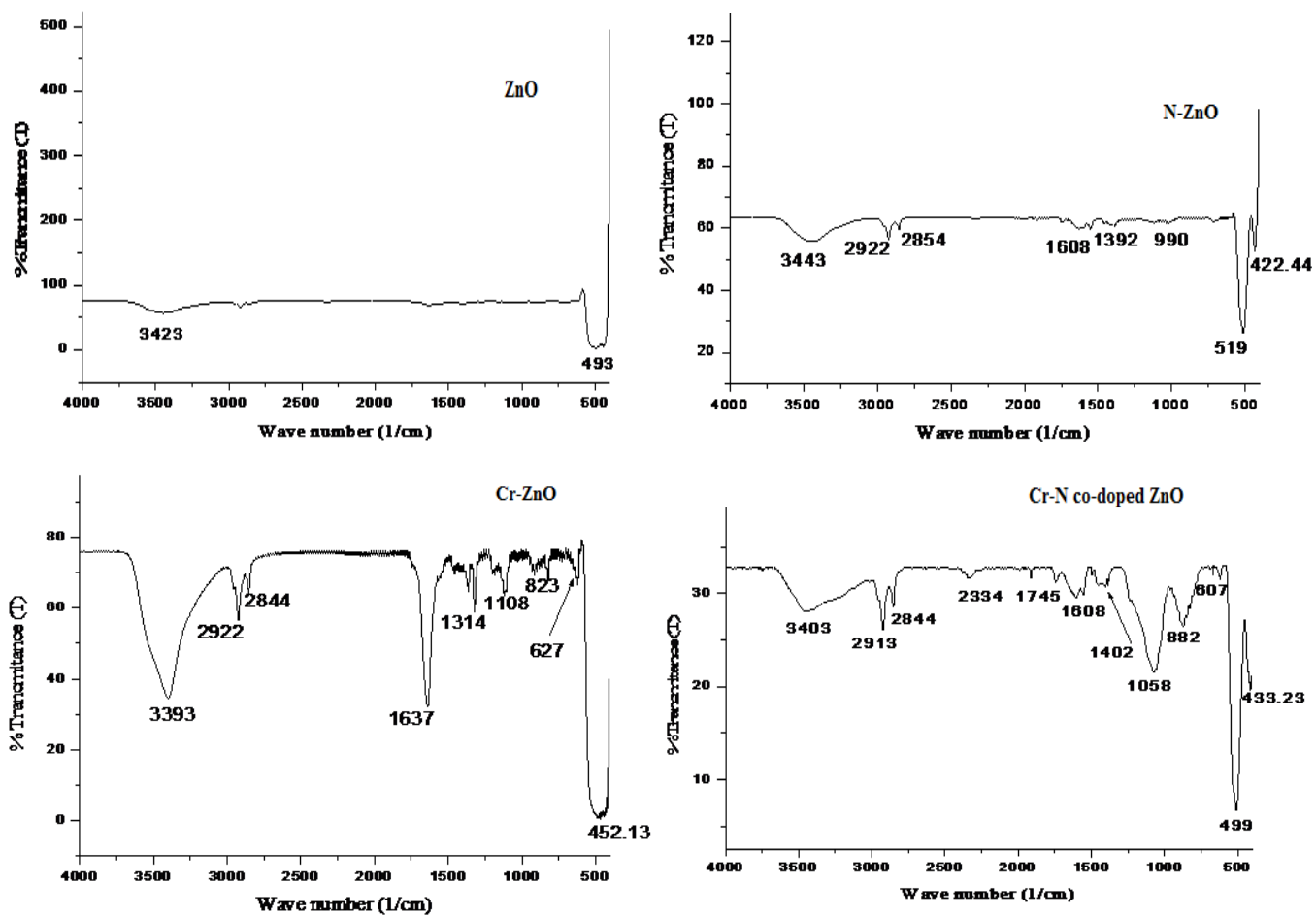

Figure 5. FTIR spectra of: a) calcined $\mathrm{ZnO}$, b) $\mathrm{N}-\mathrm{ZnO}$, c) $\mathrm{Cr}-\mathrm{ZnO}$ and d) $\mathrm{Cr}-\mathrm{N}-\mathrm{ZnO}$.

\section{Photocatalytic degradation study}

To assess and to compare the photocatalytic activities of the doped- and co-doped $\mathrm{ZnO}$ samples, the degradation reactions of aqueous solution of thymol blue (TB) were performed as photoreaction probes under UV and visible irradiation. The course of thymol blue photodecomposition using the as-synthesized catalysts is given in Table 3. The sorption/desorption equilibrium done under dark was to serve as blank and the percent photodegradation values of thymol blue dye under both UV and solar irradiation were obtained after subtracting the corresponding percent adsorption values without irradiation. The following general trends are observed in terms of degradation efficiency of the dye under consideration. In general, the photocatalytic activity of doped- and co-doped $\mathrm{ZnO}$ samples were found to be higher than the undoped $\mathrm{ZnO}$ both under solar as well as UV irradiation.

The order of efficiency of photodegradation followed $\mathrm{CrN}-\mathrm{ZnO}>\mathrm{NZnO}>\mathrm{CrZnO}>$ $\mathrm{ZnO}>\mathrm{ZnO}$ (commercial) for the visible irradiation and $\mathrm{CrN}-\mathrm{ZnO}>\mathrm{CrZnO}>\mathrm{NZnO}>\mathrm{ZnO}>$ $\mathrm{ZnO}$ (commercial) for UV irradiation. We used commercial $\mathrm{ZnO}$ as a reference to check the performance of the as-synthesized undoped $\mathrm{ZnO}$. The order in the case of the visible irradiation corresponds to the degree of red-shift observed by the as-synthesized materials. In the case of UV irradiation the exchange in the order between $\mathrm{N}$ doped and $\mathrm{Cr}$ doped $\mathrm{ZnO}$ is due to a combination of effects such as increase in surface oxygen vacancies, the separation of charge carriers, modification of the band gap, and the large surface area of the $\mathrm{Cr}$ doped $\mathrm{ZnO}$ nanorod photocatalyst [18]. The photocatalytic activity of $\mathrm{CrN}$ co-doped $\mathrm{ZnO}$ is highest among the 
studied photocatalysts both under solar as well as UV irradiations. It may be due to the synergetic effect of chromium and nitrogen co-doping in enhancing the photocatalytic activity.

Table 3. Percent adsorption and degradiation values of TB at $3 \mathrm{~h}$ under no-irradiation, visible, and UV radiation.

\begin{tabular}{|c|c|c|c|}
\hline Photocatalysts & $\begin{array}{c}\text { \%Adsorption TB } \\
\text { without irradiation }\end{array}$ & $\begin{array}{c}\text { \% Degradiation of TB } \\
\text { under visible irradiation }\end{array}$ & $\begin{array}{c}\text { \% Degradiation of } \\
\text { TB Under UV }\end{array}$ \\
\hline $\mathrm{ZnO}$ commercial & 4.2 & 31.3 & 19.2 \\
\hline $\mathrm{ZnO}$ & 5.9 & 48.0 & 58.9 \\
\hline $\mathrm{N}-\mathrm{ZnO}$ & 2.7 & 87.0 & 59.5 \\
\hline $\mathrm{Cr}-\mathrm{ZnO}$ & 3.4 & 78.1 & 68.2 \\
\hline $\mathrm{Cr}-\mathrm{N}-\mathrm{ZnO}$ & 6.3 & 98.9 & 78.5 \\
\hline
\end{tabular}

\section{Kinetic studies of photocatalytic degradation of TB}

The adsorption of thymol blue under no irradiation and its photocatalytic degradation under UV and visible irradiations follow pseudo first-order reaction kinetics $\left(\mathrm{R}^{2}>0.972\right.$, Table 4$)$ expressed by the equation:

$\ln \frac{\mathrm{C}_{0}}{\mathrm{C}_{\mathrm{t}}}=\mathrm{kt}$

where $\mathrm{k}$ is the reaction rate constant, $\mathrm{C}_{0}$ is the initial concentration of aqueous thymol blue, and $\mathrm{C}_{\mathrm{t}}$ is the concentration of aqueous thymol blue at the reaction time $\mathrm{t}$.

Table 4. Regression $\left(\mathrm{R}^{2}\right)$ values of the photocatalysis for the kinetics study.

\begin{tabular}{|l|c|c|c|}
\hline Photocatalysts & Without-irradiation & Visible-irradiation & UV-irradiation \\
\hline $\mathrm{ZnO}$ commercial & 0.989 & 0.982 & 0.989 \\
\hline $\mathrm{ZnO}$ & 0.986 & 0.996 & 0.992 \\
\hline $\mathrm{N}-\mathrm{ZnO}$ & 0.982 & 0.991 & 0.989 \\
\hline $\mathrm{Cr}-\mathrm{ZnO}$ & 0.972 & 0.992 & 0.990 \\
\hline $\mathrm{Cr}-\mathrm{N}-\mathrm{ZnO}$ & 0.986 & 0.994 & 0.994 \\
\hline
\end{tabular}

Table 5. Rate constant for TB under dark, visible and UV irradiation using different as-synthesized photocatalysts.

\begin{tabular}{|l|c|c|c|}
\hline Photocatalysts & $\begin{array}{c}\mathrm{k} \text { (without irradiation) } \\
\times 10^{+4}(\mathrm{~min})\end{array}$ & $\begin{array}{c}\mathrm{k} \text { (under visible } \\
\text { irradiation }) \times 10^{+3}(\mathrm{~min})\end{array}$ & $\begin{array}{c}\mathrm{k} \text { (under UV irradiation) } \\
\times 10^{+3}(\mathrm{~min})\end{array}$ \\
\hline $\mathrm{ZnO}$ Commercial & 2.39 & 2.08 & 1.18 \\
\hline $\mathrm{ZnO}$ & 2.89 & 4.94 & 3.63 \\
\hline $\mathrm{N}-\mathrm{ZnO}$ & 1.39 & 11.31 & 5.02 \\
\hline $\mathrm{Cr}-\mathrm{ZnO}$ & 1.89 & 8.44 & 6.37 \\
\hline $\mathrm{Cr}-\mathrm{N}-\mathrm{ZnO}$ & 3.11 & 22.30 & 8.53 \\
\hline
\end{tabular}

Adsorption rate constant $(\mathrm{k})$ values of thymol blue (TB) without irradiation, under UV and visible irradiations are shown in Table 5 and Figure 7. The rate of sorption of the thymol blue in the absence of irradiation is 10 fold less than the efficiency when it is irradiated indicating the importance of the photo source for enhancing the photocatalytic activity. Comparing the rate constants of the photocatalysts between the UV and visible irradiations, the rate constant is 1.3 to 2.6 times higher in the visible than the UV source. The increment in the rate constant is higher in the doped and co-doped cases evidencing the band manipulation 
obtained to harvest more of the visible irradiation, an advantage that would be gained in running such experiment using sunlight where the visible portion is much more than the UV portion of the solar spectrum.
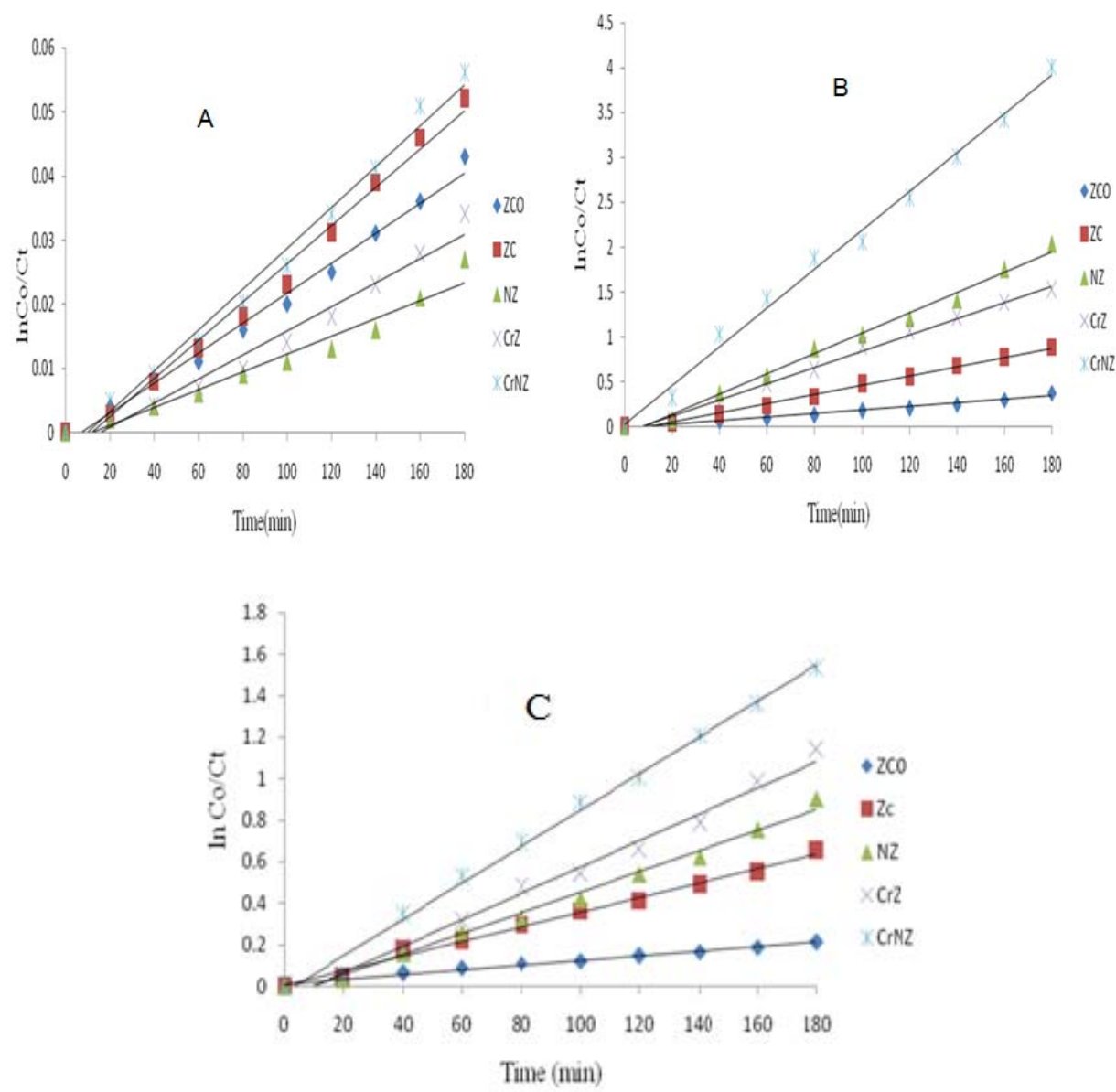

Figure 7. Plots of $\ln (\mathrm{Co} / \mathrm{Ct})$ versus time for adsorption and degradiation of TB under dark (A), visible (B), and UV irradiation (C), using different as-synthesized photocatalysts.

\section{Mechanism of photo-catalytic degradation over Cr-N co-doped ZnO}

When a photon of suitable energy ( $\mathrm{h}$ ) equal to or more than the band gap interacts with the photo-catalyst particle, an electron is excited from its valence band (VB) to the conduction band (CB) leaving behind a positively charges hole $\left(\mathrm{h}^{+}\right)$at the VB. These charge carriers (electronhole pair) can either recombine or may involve in a series of redox reactions. The hole $\left(\mathrm{h}^{+}\right)$may also interact with $\mathrm{OH}^{-}$ions or $\mathrm{H}_{2} \mathrm{O}$ molecule to produce highly reactive ${ }^{\circ} \mathrm{OH}$ radical. The excited electron at the VB reacts with the surface adsorbed $\mathrm{O}_{2}$ molecule to form superoxide radical $\left(\mathrm{O}_{2}^{-}\right)$that subsequently, with $\mathrm{H}^{+}$ions through a series of steps generate $\mathrm{HO}_{2}{ }^{-}$radical, $\mathrm{H}_{2} \mathrm{O}_{2}$ and then hydroxyl radical $\left({ }^{\circ} \mathrm{OH}\right)$. Ultimately, highly oxidant ${ }^{\circ} \mathrm{OH}$ radical react with the substrate 
(dye) to degrade it forming simple non-toxic products such as $\mathrm{CO}_{2}, \mathrm{H}_{2} \mathrm{O}$, etc. Besides, the photo-generated highly oxidizing hole $\left(\mathrm{h}^{+}\right)$can also degrade the substrate. As mentioned, earlier, the doped $\mathrm{Cr}$ and $\mathrm{N}$, synergistically, enhance photocatalytic activity by extending photoabsorptions to visible region and by minimizing the electron-hole recombination. The synergistic effect of the codoped $\mathrm{ZnO}$ in degrading the thymol blue is also witnessed by previous reports made on $\mathrm{AgN}$-codoped $\mathrm{ZnO}$ employed for degrading methyl red [28].

The various reaction steps involved in photocatalytic degradation of dye are described below:

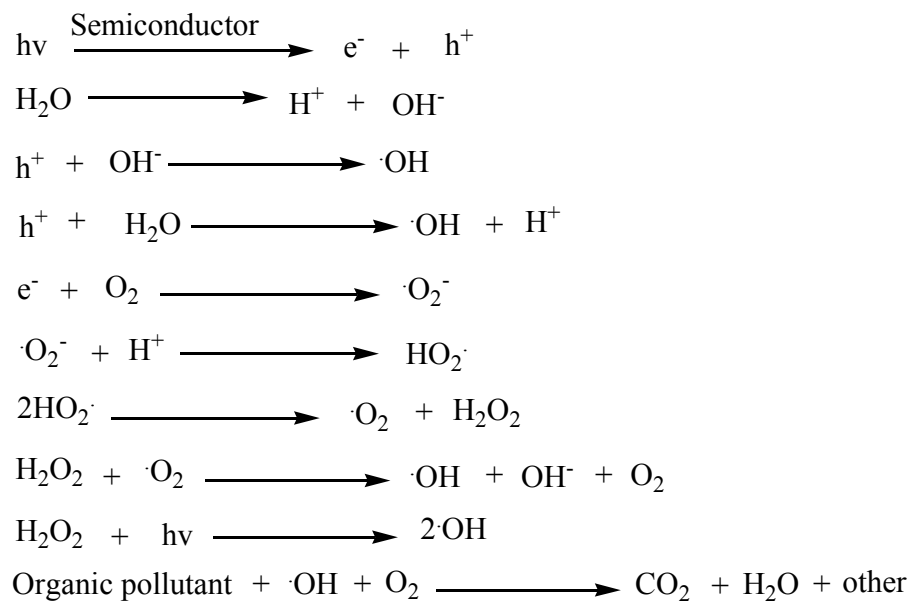

\section{CONCLUSION}

$\mathrm{Cr}-\mathrm{N}$ codoped $\mathrm{ZnO}$ has been synthesized for the first time via a one step impregnation. The photocatalytic efficiency of this composite was checked against a model pollutant, thymol blue. $\mathrm{ZnO}$, N-doped $\mathrm{ZnO}, \mathrm{Cr}$-doped $\mathrm{ZnO}$ and $\mathrm{Cr}-\mathrm{N}$ codoped $\mathrm{ZnO}$ were characterized by XRD, SEMEDX, FTIR, and UV-Vis spectroscopic techniques. The XRD analysis results indicate that all the as-synthesized photocatalysts were hexagonal wurtzite crystalline structure. The optical band gap calculated using UV-visible absorption spectra showed a remarkable red shift because of co-doping of $\mathrm{Cr}$ and $\mathrm{N}$ in $\mathrm{ZnO}$. The SEM image revealed change in morphology due to doping and presence of $\mathrm{Cr}$ in the host crystal was evidenced from the EDX spectra. The photocatalytic degradation of thymol blue using as-synthesized nanomaterials follows pseudofirst order kinetics. The highest photocatalytic efficiency of the $\mathrm{Cr}-\mathrm{N}$ co-doped $\mathrm{ZnO}$ among the studied photo-catalysts may be attributed to the synergistic effect of the co-dopants.

\section{ACKNOWLEDGEMENTS}

ID is grateful to CSIC for her research leave at AAU and HU. The financial support from the Spanish Government MINECO (project MAT2012-31127) is acknowledged. The authors also would like to thank Haramaya University for the research support granted through the School of Graduate Studies. 


\section{REFERENCES}

1. Soutsas, K.; Karayannis, V.I.; Poulios, A.; Riga, K.; Ntampegliotis, X. Desalination 2010, 250,345 .

2. Ghorai, T.K.; Soumya, K.B.; Panchanan, P. Appl. Surf. Sci. 2008, 254, 7498.

3. Chatterjee, D.; Shimanti, D. Photochem. Rev. 2005, 6, 186.

4. Sakthivel S.; Janczarek, M.; Kisch, H. J. Phys. Chem. 2004, 108, 19384.

5. Wang, C.; Wang, X.; Xu, B.Q.; Zhao, J.B.; Peng, G.; Fu, J. J. Photochem. Photobiol. A Chem. 2004, 168, 47.

6. Rana, S.B.; Singh, P.; Sharma, A.K.; Carbonari, A.W.; Dogra, R. J. Optoelect. Adv. Mater. 2010, $12,257$.

7. Colis, S.; Bieber, H.; Begin-Colin, S.G.; Schmerber, C.; Dinia, A. Chem. Phys. Lett. 2006, 422, 529.

8. Chi-Jung, C.; Tsung-Lin, Y.; Yu-Ching, W. J. Solid State Chem. 2014, $214,101$.

9. Changle, W.; Li, S.; Yong-Cai, Z.; Qingli H. Mater. Lett. $\quad$ 2011, 65, 1794.

10. Di L.; Hajime, H. J. Photochem. Photob. A: Chem. 2003, 155, 171.

11. Biju, M; Rajbongshi, A.R; Samdarshi, S.K. Mater. Lett. 2014, 134, 111.

12. Chen, C.C.; Ping, L.; Chun, H.L. Chem. Eng. J. 2008, 144, 509.

13. Buddee, S.; Sumpun, W.S.; Walailak, P. Mater. Chem. Phys. 2011,126, 167.

14. Zheng, L.R.; Zheng, Y.H.; Chen, C.Q.; Zhan, Y.Y.; Lin, X.Y.; Zheng, Q.; Wei, K.M.; Zhu, J.F. Inorg Chem. 2009, 48, 1819.

15. Xu, C.; Cao, L.; Su, G.; Liu, W.; Qu, X.; Yu, Y. J. Alloys Compd. 2010, 497, 373-376.

16. Hong, R.Y.; Li, J.H.; Chen, L.L.; Liu, D.Q.; Li, H.Z.; Zheng, Y.; Ding, J. Powd. Tech. 2009, 189, 426.

17. Richa, B,; Prashant, K.; Amit, K.; Sanjeev, K.; Ramesh, C.; Avinash, C.; Pandey, N.K. Mater. Chem. Phys. 2011,125, 664.

18. Xu, C.; Yang, K.Y.; Liu, L.; Huang, H.; Lee, J.; Cho, H.; Wang, J. Phys. Chem. C 2008, 112,19236

19. Lv, J.; Gong, Huang, W.K.; Zhu, J.; Meng, F.; Song, X.; Sun, Z. Superlatt.Microstruc. 2011, $50,98$.

20. Lin, H.F.; Liao, S.C.; Hung, S.W. J. Photochem. Photobiol. A. Chem. 2005, 174, 82.

21. Shama, R.; Ruh, U.; Butt, A.M.; Gohar, N.D. J. Hazard. Mater. 2009, 170560.

22. Qiu, X.Q.; Li, L.P.; Zheng, J.; Liu, J.J.; Sun, X.F.; Li, G.S. J. Phys. Chem. C 2008, 112, 12242.

23. Cao, Y.Q.; He, T.; Chen, Y.M.; Cao, Y.A. J. Phys. Chem. C 2010, 114, 3627.

24. El-Kemary, M.; El-Shamy, H.; El-Mehasseb, I. J. Lumen. 2010, 130, 2327.

25. Ahmed, F.; Shalendr, K.; Nishat, A.; M.S.; Anwar, S.Y.; Lee, K.; Gyung-Suk, P.; Dae-Won, H.K.; Bon, G.L. Thin Solid Films 2011, 519, 8375.

26. Sanith, J.; Santhoskumar, A.U.; Bhuvanan, K.P.; Palanivelu, K.; Nayak, S.K. Mater. Sci. Semicond. Process. 2012, 15, 326.

27. Yang, L.; Jinghai, Y.; Qingfeng, G.; Lili, Y.; Yongjun, Z.; Yaxin,W.; Bo, F.; Jian, C.; Xiaoyan, L.; Yanting, Y.; Maobin,W. J. Alloys Compounds 2009, 486, 835.

28. Welderfael, T.; Yadav, O.P.; Tadesse, A.M.; Kaushal, J. Bull. Chem. Soc. Ethiop. 2013, 27, 221. 